05

\title{
Поляризационно-зависимая филаментация фемтосекундных лазерных импульсов в синтетическом алмазе
}

\author{
(C) Г.К. Красин, Н.Г. Сцепуро, В.П. Мартовицкий, М.С. Ковалев \\ Физический институт им. П.Н. Лебедева, \\ 119991 Москва, Россия \\ e-mail: krasin.georg@gmail.com
}

Поступила в редакцию 20.12.2021 г.

В окончательной редакции 20.12.2021 г.

Принята к публикации 30.12.2021 г.

\begin{abstract}
Проведено исследование процесса филаментации внутри объема синтетического алмаза ІІа-типа с известной кристаллографической ориентацией в зависимости от состояния поляризации ультракоротких лазерных импульсов длительностью $300 \mathrm{fs}$ и длиной волны $515 \mathrm{~nm}$. Коэффициент пропускания образца измерялся с помощью фотодиода, а микроизображение филамента регистрировалось на КМОП-камере перпендикулярно оси распространения возбуждающего лазерного излучения. Зависимости коэффициента пропускания и длины филамента от азимута поляризации показывают отчетливую модуляцию на всем диапазоне его изменения.
\end{abstract}

Ключевые слова: ультракороткие лазерные импульсы, синтетический алмаз, фотолюминесценция, лазерная поляризация, нелинейное поглощение, широкозонные диэлектрики.

DOI: $10.21883 /$ OS.2022.04.52263.61-21

\section{Введение}

В настоящее время стремительно развиваются инновационные методы характеризации оптически прозрачных материалов, в том числе определение оптических параметров материала, исследование его уникальных свойств, а также изучение различных дефектов в объеме. Поэтому при полноценном исследовании различных материалов появляется возможность контролируемой и высококачественной модификации материалов различными способами. Одним из перспективных для науки, техники и промышленности способов является модификация материала ультракороткими лазерными импульсами различной длительности. В рамках данного способа, очевидно, что эффективной технологией является нано- и микроструктурирование на поверхности [1-4] и в объеме материала с помощью прямой лазерной записи [5-9]. Эта технология позволяет записывать наноструктуры различной формы и конфигурации, производить дифракционные оптические элементы, генерировать микродефекты в объеме материала. Очевидно, что для корректной и качественной модификации поверхности/объема следует изучить различные механизмы взаимодействия лазерного излучения с материалом.

Хорошо известно, что взаимодействие материала с лазерным излучением зависит преимущественно от его характеристик - интенсивности, длины волны, частоты следования импульсов и их длительности, поляризации $[10,11]$. Чаще всего состояние поляризации излучения выбирается случайным образом или без обоснования, хотя оно может влиять на скорость фотоио- низации вдоль разных кристаллографических направлений материала и сильно отличается из-за различной ширины запрещенной зоны в зоне Бриллюэна $[12,13]$. Известны работы [14-16], исследующие зависимость порога разрушения поверхности материала от состояния поляризации. В работах [17-19] исследовалось влияние состояния поляризации на фотовозбуждение кристаллических материалов: сапфира, кремния и алмаза с различными ориентациями. В качестве объемных эффектов исследовалось влияние различных состояний поляризации на процесс филаментации (в воздухе [20,21] и диэлектриках [22,23]).

Таким образом, поляризация является параметром лазерного излучения, который в силу высокой нелинейности фотовозбуждения может оказывать значительное влияние на проходящие процессы внутри объема кристаллов, в особенности в широкозонных алмазах. В настоящей статье изучался эффект влияния вращения азимута поляризации лазерных импульсов фемтосекундной длительности на процесс филаментации в объеме синтетического алмаза с ориентациями граней (001) и (110).

\section{Экспериментальная часть}

В настоящей работе использовалось излучение второй гармоники $\lambda=515 \mathrm{~nm}$ с линейным состоянием поляризации, генерируемое фемтосекундным лазером Satsuma. Длительность импульсов составила $\tau \approx 300 \mathrm{fs}$, а энергия падающих на образец импульсов $E_{\max }=250 \pm 1 \mathrm{~nJ}$ в режиме $\mathrm{TEM}_{00}$. Лазерное излучение фокусировалось в объеме алмаза с помощью микрообъектива (с числовой 


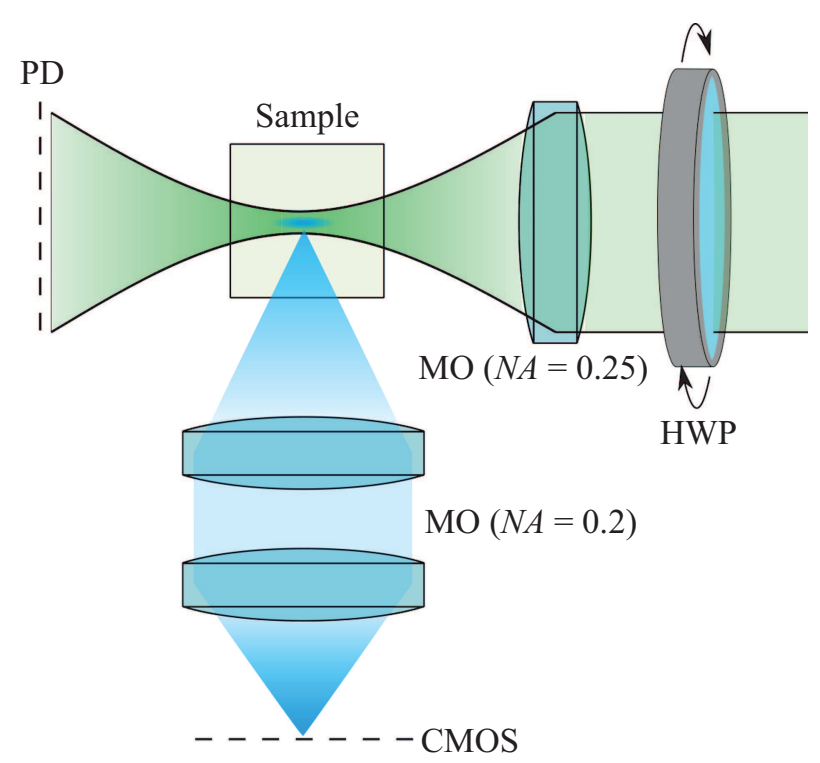

Рис. 1. Схема экспериментальной устрановки: HWP - полуволновая пластинка, МО - микрообъектив, PD - фотодиодный измеритель энергии, CMOS - КМОП-камера.

апертурой $N A=0.25)$ в пятно с радиусом $R_{1 / \mathrm{e}} \approx 2.1 \mu \mathrm{m}$ (рис. 1). Азимут поляризации возбуждающего излучения изменялся в диапазоне $0-360^{\circ}$ с шагом $15^{\circ}$ с помощью полуволновой пластинки, установленной перед микрообъективом. Образец представлял собой чистый синтетический алмаз с габаритами $1.5 \times 1.5 \times 3 \mathrm{~mm}$, грани которого были предварительно отполированы до оптического качества поверхности. Основные кристаллографические ориентации (4 грани $\{110\}$ и 2 грани $\{001\})$ и направления в плоскостях алмаза были определены на установке рентгеновской дифракции Panalytical X'Pert Pro MRD Extended.

Излучение, прошедшее через алмаз, регистрировалось с помощью фотодиодного сенсора (Ophir PD10-C, апертура $10 \mathrm{~mm}$, спектральный диапазон $0.19-1.1 \mu \mathrm{m}$, диапазон энергий $1 \mathrm{~nJ}-15 \mu \mathrm{J})$, который выступал в роли измерителя энергии импульсов. Далее образец убирался, и измерялась энергия, падающая на образец. Затем рассчитывались относительные значения коэффициента пропускания образца в зависимости от состояния поляризации. Погрешность измерения энергии с помощью фотодиодного сенсора составила $0.5 \%$. Визуализация области фотолюминесценции (ФЛ) производилась перпендикулярно оси распространения лазерных импульсов при помощи кварц-флюоритового микрообъектива (с числовой апертурой $N A=0.2$ ) и КМОП-камеры (монохромная КМОП-камера Thorlabs CS2100M-USB, разрешение $1920 \times 1080$, размер пиксела $5.04 \mu \mathrm{m}$ и динамический диапазон до $87 \mathrm{~dB}$ ). Для получения стабильного микроизображения филамента на камере частота следования импульсов в экспериментах составляла $100 \mathrm{kHz}$.

\section{Экспериментальные результаты и их обсуждение}

Для изучения влияния азимута поляризации возбуждающего излучения на процесс филаментации предварительно были проведены измерения коэффициента пропускания фемтосекундных импульсов, сфокусированных на глубине $500 \mu \mathrm{m}$, через синтетический CVD-алмаз. Излучение заводилось внутрь алмаза через грань (001), которая является гранью 4-й степени симметрии, поэтому при постройке азимутальных зависимостей в полярных координатах можно ожидать четырехлепестковые поляризационные диаграммы $[24,25]$. Действительно, на рис. 2, $a$ отчетливо прослеживается азимутальная модуляция пропускания через образец с предельным отклонением в пропускании, составляющим $\sim 11 \%$ от максимального значения.

Одновременно с регистрацией пропускания образца проводилась визуализация ФЛ под прямым углом, где были зарегистрированы микроизображения филамента на монохромной КМОП-камере. Филаментация начинается, когда мощность излучения превышает критическую мощность самофокусировки материала, которая для алмаза принимает значения в диапазоне $P_{\mathrm{cr}}=0.4-2 \mathrm{MW}$ для видимых и ИК лазерных импульсов [26]. Для исследования процесса филаментации были измерены и построены в полярных координатах зависимости длины филамента (рис. 2,b), а также смещения максимума интенсивности филамента относительно начального положения в сторону геометрического фокуса (рис. 2,c). Как можно наблюдать из графиков, эти зависимости также имеют 4-лепестковое распределение. Наблюдаемые зависимости пропускания и длины филамента находятся в противофазе, поскольку возбуждение ФЛ обеспечивается внутренним нелинейным поглощением алмаза. Соответственно в зонах с минимальным коэффициентом пропускания наблюдается максимум ФЛ и наоборот (при данной интенсивности фемтосекундных импульсов).

Полученные азимутальные зависимости можно связать с изменением критической мощности самофокусировки в объеме алмаза при вращении азимута поляризации фемтосекундных лазерных импульсов и ориентации вектора поляризации относительно различных направлений в зоне Бриллюэна. Так, для начального положения $\left(0^{\circ}\right)$ поглощение является максимальным для данной ориентации кристалла, область, в которой образуется филамент, является наибольшей, и сам филамент начинается ближе к границе раздела сред навстречу возбуждающему излучению. Далее, при изменении азимута вплоть до $45^{\circ}$ наблюдается падение поглощения и, как следствие, уменьшение длины филамента с его последующим укорочением в направлении геометрического фокуса в глубине алмаза. Таким образом, управляя азимутом поляризации фемтосекундных импульсов, можно эффективно управлять нелинейностью фотовозбуждения в соответствующей области зонного спектра и, как следствие, процессом филаментации. 

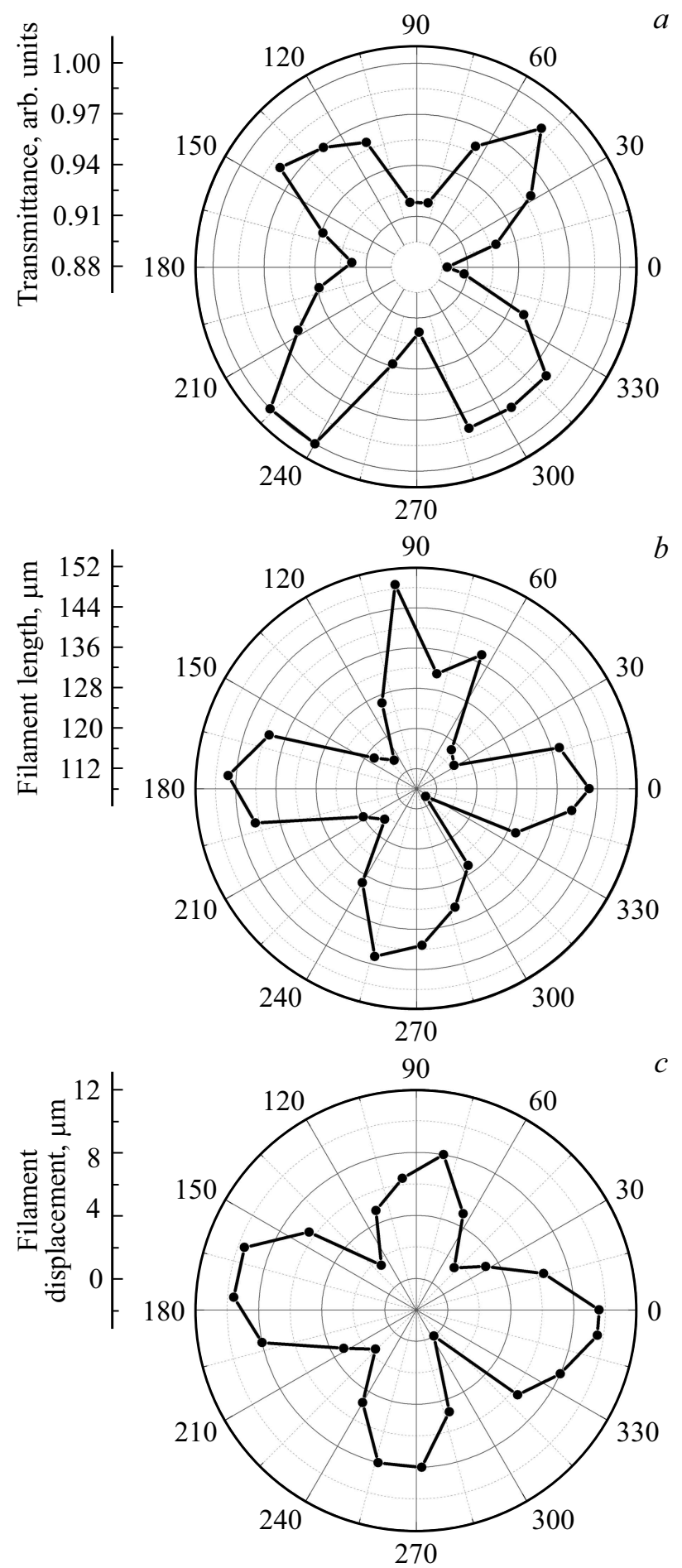

Рис. 2. Азимутальные зависимости коэффициента пропускания образца $(a)$, длины филамента $(b)$ и смещения максимума филамента вдоль оси распространения излучения в направлении геометрического фокуса $(c)$, представленные в полярных координатах.

\section{Заключение}

В результате исследования процесса филаментации внутри объема синтетического алмаза ІІа-типа были получены зависимости коэффициента пропускания образца и длины филамента от азимута поляризации ультракоротких лазерных импульсов длительностью $300 \mathrm{fs}$ на длине волны $515 \mathrm{~nm}$. Эти зависимости образуют четырехлепестковые поляризационные диаграммы, которые согласуются со степенью симметрии оси (4 порядка), через которую производилось возбуждение ФЛ и измерялось пропускание. Полученные зависимости связываются с изменением критической мощности самофокусировки в объеме синтетического алмаза при изменении лазерной поляризации и ориентации вектора излучения относительно различных направлений в зоне Бриллюэна.

\section{Финансирование работы}

Исследование выполнено при финансовой поддержке Российского научного фонда (проект № 21-79-30063).

\section{Конфликт интересов}

Авторы заявляют, что у них нет конфликта интересов.

\section{Список литературы}

[1] A.J. Traverso, J. Huang, T. Peyronel, G. Yang, T.G. Tiecke, M.H. Mikkelsen. Optica, 8 (2), 202 (2021). DOI: $10.1364 /$ OPTICA.400731

[2] V. Kesaev, A. Nastulyavichus, S. Kudryashov, M. Kovalev, N. Stsepuro, G. Krasin. Opt. Mater. Express, 11 (7), 1971 (2021). DOI: 10.1364/OME.428047

[3] S.I. Kudryashov, T. Pflug, N.I. Busleev, M. Olbrich, A. Horn, M.S. Kovalev, N.G. Stsepuro. Opt. Mater. Express, 11 (1), 1 (2021). DOI: 10.1364/OME.412790

[4] R. Zazo, J. Solis, J.A. Sanchez-Gil, R. Ariza, R. Serna, J. Siegel. Appl. Surf. Sci., 520, 146307 (2020). DOI: $10.1016 /$ j.apsusc. 2020.146307

[5] B.N. Chichkov, C. Momma, S. Nolte, F. von Alvensle-ben, A. Tünnermann. Appl. Phys. A, 63, 109 (1996). DOI: $10.1007 / \mathrm{BF} 01567637$

[6] C. Liu, X.L. Mao, S.S. Mao, X. Zeng, R. Greif, R.E. Russo. Anal. Chem., 76 (2), 379 (2004). DOI: 10.1021/ac035040a

[7] K.-H. Leitz, B. Redlingshofer, Y. Reg, A. Otto, M. Schmidt. Phys. Procedia, 12 (B), 230 (2011). DOI: $10.1016 /$ j.phpro.2011.03.128

[8] A.A. Kuchmizhak, A.P. Porfirev, S.A. Syubaev, P.A. Danilov, A.A. Ionin, O.B. Vitrik, Yu.N. Kulchin, S.N. Khonina, S.I. Kudryashov. Opt. Lett., 42 (14), 2838 (2017). DOI: $10.1364 /$ OL. 42.002838

[9] А.Е. Рупасов, П.А. Данилов, М.П. Смаев, М.С. Ковалёв, А.С. Золотько, А.А. Ионин, С.И. Кудряшов. Опт. и спектр., 128 (7), 918 (2020). DOI: 10.21883/OS.2020.07.49564.48-20 [A.E. Rupasov, P.A. Danilov, M.P. Smaev, M.S. Kovalev, A.S. Zolot'ko, A.A. Ionin, S.I. Kudryashov. Opt. Spectr., 128, 928 (2020). DOI: 10.1134/S0030400X20070188].

[10] P. Balling, J. Schou. Rep. Prog. Phys., 76, 036502 (2013). DOI: $10.1088 / 0034-4885 / 76 / 3 / 036502$ 
[11] Д.А. Заярный, А.А. Ионин, С.И. Кудряшов, С.В. Макаров, А.А. Кучмижак, О.Б. Витрик, Ю.Н. Кульчин. Письма в ЖЭТФ, 103 (12), 846 (2016). [D.A. Zayarny, A.A. Ionin, S.I. Kudryashov, S.V. Makarov, A.A. Kuchmizhak, O.B. Vitrik, Yu.N. Kulchin. JETP Lett., 103 (12), 752 (2016). DOI: 10.1134/S0021364016120158].

[12] D.J. Little, M. Ams, P. Dekker, G.D. Marshall, J.M. Dawes, M.J. Withford. Opt. Express, 16(24), 20029 (2008). DOI: $10.1364 /$ OE.16.020029

[13] V.V. Temnov, K. Sokolowski-Tinten, P. Zhou, A. El-Khamhawy, D. von der Linde. Phys. Rev. Lett., 97, 23 (2006). DOI: 10.1103/PhysRevLett.97.237403

[14] A.P. Joglekar, H. Liu, E. Meyhöfer, G. Mourou, A.J. Hunt. PNAS, 101 (16), 5856 (2004). DOI: $10.1073 /$ pnas.0307470101

[15] D. Liu, Y. Li, M. Liu, H. Yang, Q. Gong. Appl. Phys. B, 91, 597 (2008). DOI: 10.1007/s00340-008-3022-6

[16] L.A. Lompre, G. Mainfray, C. Manus, J. Thebault. Phys. Rev. A, 15 (4), 1604 (1977).

DOI: 10.1103/PhysRevA.15.1604

[17] Q. Wen, P. Zhang, G. Cheng, F. Jiang, X. Lu. Ceram. Int., 45 (17), 23501 (2019). DOI: 10.1016/j.ceramint.2019.08.056

[18] X. Zhang, L. Zhang, S. Mironov, R. Xiao, L. Guo, T. Huang. Appl. Phys. A, 127, 196 (2021).

DOI: 10.1007/s00339-021-04341-y

[19] Г.К. Красин, М.С. Ковалев, П.А. Данилов, Н.Г. Сцепуро, Е.А. Олейничук, С.А. Бибичева, В.П. Мартовицкий, С.И. Кудряшов. Письма в ЖЭТФ, $114(3), 147$ (2021). DOI: $10.31857 /$ S1234567821150015 [G.K. Krasin, M.S. Kovalev, P.A. Danilov, N.G. Stsepuro, E.A. Oleynichuk, S.A. Bibicheva, S.I. Kudryashov. JETP Lett., $114(3), 117$ (2021). DOI: 10.1134/S0021364021150054].

[20] Z. Zhu, T.-J. Wang, Y. Liu, N. Chen, H. Zhang, H. Sun, H. Guo, J. Zhang, X. Zhang, G. Li, C. Liu, Z. Zeng, J. Liu, S.L. Chin, R. Li, Z. Xu. Chin. Opt. Lett., 16(7), 073201 (2018). DOI: 10.3788/COL201816.073201

[21] S. Mitryukovskiy, Y. Liu, P. Ding, A. Houard, A. Couairon, A. Mysyrowicz. Phys. Rev. Lett., 114, 063003 (2015). DOI: 10.1103/PhysRevLett.114.063003

[22] J. Chang, R. Zhu, T. Xi, M. Xu, D. Wang, L. Zhang, D. Li, Z. Hao. Chin. Opt. Lett., 17 (12), 123201 (2019). DOI: 10.3788/COL201917.123201

[23] M.M. Brundavanam, P.K. Velpula, N.R. Desai. In: Proc. of Tenth Int. Conf. on Fiber Optics and Photonics (SPIE, 2011), 8173, 81730P. DOI: $10.1117 / 12.897913$

[24] K. Kobashi. Diamond films: chemical vapor deposition for oriented and heteroepitaxial growth, 1st ed. (Elsevier, 2005). DOI: 10.1016/B978-0-08-044723-0.X5000-4

[25] П.П. Феофилов. УФН, 58 (1), 69 (1956). DOI: $10.3367 /$ UFNr.0058.195601c.0069.

[26] S.I. Kudryashov, A.O. Levchenko, P.A. Danilov, N.A. Smirnov, A.A. Ionin. Opt. Lett., 45 (7), 2026 (2020).

DOI: $10.1364 /$ OL.389348 